\title{
Organ procurement surgery as a means of increasing open surgical experience during urology residency training
}

\author{
Nathan A. Hoag, MD, Ryan Flannigan, MD, Andrew E. MacNeily, MD, FRCSC
}

Department of Urologic Sciences, Division of Pediatric Urology, University of British Columbia, Vancouver, BC

See related article on page 39.

Cite as: Can Urol Assoc J 2014;8(1-2):36-8. hitp://dx.doi.org/10.5489/cuaj.1497

Published online February 10, 2014.

\section{Abstract}

Introduction: The introduction and advancement of minimally invasive surgery (MIS) has resulted in a reciprocal decline in exposure to open surgery during urology residency training. We propose organ procurement surgery as a potential vehicle to facilitate an increase in open surgical experience among trainees. We define the surgical case volume for organ procurement surgeries currently performed by urology residents in Canada, and determine what capacity exists for expansion.

Methods: Data on organ procurement surgeries were extracted for Canadian urology residents case-logs between 2005 and 2009. Case-logs were anonymously analyzed through the voluntary self-reporting program T-Res (Resilience Software Inc.). National deceased organ donor data were obtained from the Canadian Institute for Health Information.

Results: The graduating Canadian urology resident has performed an average of 0.95 organ procurement surgeries during 5 years of training. An average of 469.6 procurement surgeries were performed yearly in Canada between 2005 and 2009. The theoretical capacity exists for each graduating resident to perform an additional 16.3 organ procurements during residency.

Conclusions: With the establishment of MIS as standard of care for many urologic surgeries, the decrease in open operative experience is concerning. Innovative ways to enrich open surgical experience may be required, and increased formal incorporation of organ procurements into urology residency training curriculum may help fill the void.

\section{Introduction}

Open surgical techniques have traditionally been the gold standard in urologic surgery and post-graduate residency training programs. However, exposure to open techniques has become endangered due to shifting practice patterns. ${ }^{1}$ With the wide acceptance of minimally invasive surgery (MIS) and the introduction of more conservative treatment options that had in the past required open surgery, the proportion of open surgical cases during Canadian urologic residency has declined. ${ }^{2}$ The steady drop in open surgical volume raises concerns about the proficiency among graduating urology residents, yet the effect remains unknown. ${ }^{3}$

MIS techniques have supplanted the open approach for many urologic procedures, including nephrectomy. ${ }^{4}$ Practice patterns have corroborated this increased use of MIS techniques in academic and community urology settings. ${ }^{5}$ The trend toward increasing exposure to MIS approaches and a reciprocal decrease in open surgery is also true among urology residents in the United States and Canada. ${ }^{2,4,6}$

Mamut and colleagues described the resident-reported experience in Canadian residency training programs for index surgical procedures between 2003 and 2009. They found that open surgery remained the most often reported operative technique; however, MIS cases increased significantly, while conventional open techniques declined during the time period. ${ }^{2}$

Given the broadening application of MIS techniques in academic and community urologic practice, training for these techniques is increasingly important, and is appropriately reflected in current residency programs. However, open surgical techniques remain essential in a urologist's armamentarium for cases not amenable to MIS, as well as for potential open conversion of cases. Compromises to open surgical case volume have not yet been objectively linked to lessened technical competence upon completing postgraduate training. ${ }^{1}$ Maintaining open surgical case volume during post-graduate surgical training is intuitively important to achieve the same open technical proficiency as previously expected.

Gunter III and colleagues identified the potential role of organ procurement in supplementing open surgical experi- 
ence among general surgery residents in the United States. ${ }^{7}$ Among graduating residents, an average of 2 organ procurements were performed during their 5-year residency. However, based upon the number of organ procurements available in their region, each resident would have had the opportunity to perform 40 organ procurements during their 5 years. These procedures require ample dissection, and identification of anatomic structures directly pertinent to surgical training in both general surgery and urology. ${ }^{7}$

Cadaveric and live donor renal harvesting for transplantation is categorized as a "Category B" surgical procedure by the Royal College of Physicians and Surgeons of Canada objectives of training in urology. This means that the graduating Canadian urology resident should know how to perform the procedure, though residents are not expected to perform this procedure independently during residency training. ${ }^{8}$ Thus, the use of organ procurement remains within the scope of urologic post-graduate training and may aid in supplementing the increasingly compromised open surgical experience present-day trainees are encountering.

We assess the current level of Canadian urology resident participation in abdominal organ procurement surgeries, and determine what potential capacity exists for expansion of resident involvement in these procedures.

\section{Methods}

Permission to review resident case-logs was obtained from the residency affairs committee of the Canadian Urological Association. Canadian urology resident case-logs were retrospectively reviewed to include the 5 academic years between 2005 and 2009 using the online, voluntary case recording database T-Res (Resilience Software Inc.). ${ }^{9}$ Data for all residents were collected anonymously, without identification of individuals or programs, to protect privacy. Using extracted data, we recorded the absolute numbers of organ retrieval operations reportedly performed between 2005 and 2009. Only resident roles listed as "primary" or "first assistant" were included, and no differentiation was made between these reported roles.

The total number of abdominal organ procurement procedures performed in Canada between 2005 and 2009 was obtained from the Canadian Organ Replacement Register through the Canadian Institute for Health Information. ${ }^{10}$

The data were tabulated, and we recorded the average participation rate of Canadian urology residents in organ procurement surgeries. The average annual number of abdominal organ procurement surgeries performed in Canada was determined and compared to resident numbers to see if increased capacity for participation in organ procurement procedures existed among Canadian urology residents.

\section{Results}

Canadian urology residents performed a total of 126 organ retrieval procedures in the academic years between 2005 and 2009. During this same period, there was an average of 27.2 Canadian urology residents per year in training, for a total of about 136 residents each year (post-graduate years 1 to 5 ). This is about 25.2 procurements per year by urology residents in Canada (or 0.19 procurements per resident, per year), for an average of 0.95 procurements per resident during their training period.

An average of 469.6 abdominal organ procurement surgeries were performed yearly in Canada between 2005 and 2009 (range: 414-493). There is a current capacity for about 17.25 organ procurements per urology resident over their 5 years of training (3.45 procurements per urology resident, per year), if urology residents in Canada attended every abdominal organ procurement surgery performed. Given the current average participation rate of 0.95 procurements during the 5 years of training, theoretical capacity exists for each Canadian urology resident to perform an additional 16.3 procurements during residency.

\section{Discussion}

With decreased resident exposure to open surgical cases, supplementation with additional procedures would naturally enhance overall trainee competency and proficiency. An American general surgical training program has proposed organ procurement procedures to facilitate an increase in open surgical exposure, with significant potential identified. ${ }^{7}$ Similarly, in Canada among the urology training programs, organ procurement is potentially under-utilized in post-graduate training programs. As we found, only 0.95 procurements were performed over 5 years, on average, by graduating Canadian urology residents. It should be noted, however, that some urology programs within Canada have minimal participation in organ transplantation. Given that 17.25 is the number of potential organ procurements to be performed by urology resident trainees over their 5-year residency, there is a significant untapped resource in open surgical experience.

Several parallels exist among the anatomy and surgical steps of organ procurement and open urologic surgery. Opening the abdomen during organ procurement involves an incision from pubis to xyphoid, spanning abdominal and pelvic compartments. This correlates to similar anatomical landmarks involved in retroperitoneal lymph node dissections, midline approach to large renal masses, and trauma nephrectomy. Pelvic anatomy is also well-exposed, as the distal aorta, iliac vessels and ureters are identified and controlled mirroring some steps in radical prostatectomies, pelvic lymph node dissections and renal transplants. Cadaveric 
Hoag et al.

donor nephrectomies are performed by mobilizing and isolating the ureter, and removing en bloc or further dissection of the renal hilum, providing the opportunity for learning valuable skills that translate into other urologic surgeries. ${ }^{11}$

It is clear that the surgical anatomy, vascular dissection and isolation, with respect to surrounding organs and surgical steps, provide experience supporting organ procurement experience in urology training programs. Of particular interest, many urology index cases (donor, radical, and simple nephrectomy, partial nephrectomy, radical prostatectomy, radical cystectomy, adrenalectomy, pyeloplasty, and nephroureterectomy) have substantive overlap with procurement surgeries. ${ }^{1,2}$ This could fill the developing void of open surgical experience in many of the cases increasingly being performed with MIS techniques. ${ }^{2}$

There are several limitations to our study. One is the fact that case-log reporting for Canadian urology residents has been voluntary, and therefore we cannot accurately tell how many cases reflect actual resident experience. There are also inherent logistical problems with increasing resident participation in organ procurement procedures. Residents are often fulfilling other clinical duties, making their availability potentially problematic. It is also unknown to what degree surgical residents from other disciplines already attend procurement surgeries. The relative infrequency of organ procurement, and the geographical variability in where these procedures take place, are both barriers to increasing resident participation. In addition, not all trainees have equal opportunity to achieve the mean of 17.25 potential organ procurements during their 5 years of residency training, owing to the fact that not all training centres involve urologists in procurement surgeries. However, our recent e-survey of urology program directors indicated that 8/12 residency training centres do involve urology faculty in cadaveric donor procurements in some capacity (personal communication, AE MacNeily, August 2013). This certainly indicates the possibility for enhancement of this surgical experience for urology residents.

Challenges do exist in incorporating formal resident participation in organ procurement surgeries within urology residency programs in Canada. However, innovative solutions must be explored to maintain adequate open surgical experiences among urology trainees to balance the advancements being made in MIS.

\section{Conclusion}

Resident exposure to open surgical procedures has been decreasing in recent years. This is largely due to the broadening role of MIS techniques in the treatment of certain urologic conditions. Organ procurement may be a viable option to enrich open surgical experience among Canadian trained urology residents. Formal inclusion of these procedures in the resident training curriculum may be of benefit to fill this void and to aid in reinforcing skill and techniques required during urologic post-graduate training.

Competing interests: Dr. Hoag, Dr. Flannigan and Dr. MacNeily all declare no competing financial or personal interests.

This paper has been peer-reviewed.

\section{References}

1. Hoag NA, Mamut AE, Afshar $\mathrm{K}$, et al. Trends in urology resident exposure to minimally invasive surgery for index procedures: A tale of two countries. I Surg Educ 2012;69:670-5.

2. Mamut AE, Afshar K, Mickelson JJ, et al. Surgical case volume in Canadian urology residency: A comparison of trends in open and minimally invasive surgical experience. J Endourol 2011;25:1063-7. http://dx.doi. org/10.1089/end.2010.0304

3. MacNeily AE. The training of Canadian urology residents: Whither open surgery? Can Urol Assoc $J$ 2010;4:47-8

4. Duchene DA, Moinzadeh A, Gill IS, et al. Survey of residency training in laparoscopic and robotic surgery. J Urol 2006;176:2158-66. http://dx.doi.org/10.1016/i.juro.2006.07.035

5. McNeill SA, Tolley DA. Laparoscopy in urology: Indications and training. BJU Int 2002;89:169-73. http:// dx.doi.org/10.1046/i.1464-4096.2001.01891.x

6. Preston MA, Blew BD, Breau RH, et al. Survey of senior resident training in urologic laparoscopy, robotics, and endourology surgery in Canada. Can Urol Assoc J 2010;4:42-6. http://dx.doi.org/10.5489/ cuaj.09036

7. Gunter III JW, Simmons JD, Mitchell ME, et al. A solution to the decreased resident exposure to open operations in the era of minimally invasive surgery and restricted duty hours may be with organ procurement and transplantation surgery. J Surg Educ 2012;69:575-9. http://dx.doi.org/10.1016/i.jsurg.2012.05.005

8. Royal College of Physicians and Surgeons of Canada: Objectives of Training in Urology. http://www. royalcollege.ca/cs/groups/public/documents/document/y2vk/mday/ edisp/tztest3rcpsced002644. pdf. Accessed January 14, 2014.

9. T-Res. http://www.tres.net/public/index.html. Accessed January 14, 2014.

10. Canadian Institute for Health Information. Canadian Organ Replacement Register. http://www.cihi.ca/ corr. Accessed January 14, 2014.

11. Krishnamurthi V. In Novick AC, ed. Cleveland Clinic Operative Urology: Surgical Technique of Cadaver Donor Nephrectomy. New Jersey: Humana Press; 2006: 103-9. http://dx.doi.org/10.1007/978-159745-016-4_8

Correspondence: Dr. Andrew E. MacNeily, BC Children's Hospital, K0-134 - 4480 0ak St., Vancouver, BC; amacneily@cw.bc.ca 